\title{
Implementation of Management Technologies for Innovative Development of the Region
}

\author{
Ayna Salamova* \\ Chechen State University, st. Sheripova 32, 364024 Grozny, Russia
}

\begin{abstract}
The transition of the Russian economy to an innovative path of development, the most complete and rational use of the economic, scientific, technical and intellectual potential of each region will largely depend on the effectiveness of management at the regional level. In this regard, there is a need to develop a methodology for the formation and implementation of management technologies for innovative development of the region. Management technologies are understood as technologies that help to reduce production costs in different sources of their occurrence, as well as are carried out through decision-making at the regional level. Management technologies for innovative development of territories should ensure the concentration of resources in priority areas and create conditions for interregional cooperation, business, public institutions within the framework of innovative development.
\end{abstract}

\section{Introduction}

The concept of long-term socio-economic development of the Russian Federation focuses on the transition of the Russian economy from the export of raw materials to an innovative socially-oriented type of development. This will make it possible to dramatically expand the competitive potential of the Russian economy by increasing its comparative advantages in science, education and high technologies and, on this basis, to use new sources of economic growth and increased welfare [1]. The leading factor of economic growth and national competitiveness in an innovative economy is becoming intellect, human creativity, and a source of high income is not only the opportunity to receive rent from the use of natural resources and high global market conditions, but also the production of new ideas, technologies and social innovations.

Particular importance in the innovation economy is given to the regions, the dynamic and stable development of which is determined by knowledge, new technologies and active representation in the world economic space. A number of priorities can be identified that reflect a new stage of territorial development and the strengthening of the role of Russian regions, including significant differentiation of functions between the center and the region, the use of public-private partnership as a fundamental mechanism for interaction between the state and the business community, etc.

*Corresponding author: salamova_chgu@mail.ru 
The innovative development of territories is based on the use of modern management technologies. In general, management technologies are understood as a set of management works and operations performed in a certain order, a certain sequence of principles and methods. If we consider the features of management technologies at the regional level, then the following can be distinguished [2]:

1. Management technologies are aimed at solving the main task facing regional government bodies.

2. In the control system, the functions, tasks and principles of management are becoming more complex. This is due to the fact that the functioning of the governing bodies has been carried out over the past 18 years in new conditions, there is a constant improvement of the legislative framework.

3. The management object is a very complex system, consisting of a large number of enterprises and organizations of different forms of ownership. In order to be able to implement a managerial decision, coordination and consistency of actions between business and government is necessary, since at present there is no effectively operating mechanism for involving business in making managerial decisions.

\section{Modern technologies of regional management}

It should also be noted that the current state of industrial production in Russian regions objectively does not allow a quick transition to an innovative path of development in the real sector of the economy. In the current conditions, the innovative development of regions should be based on modern management technologies. Management technologies at the regional level are understood as technologies that help reduce production costs in different sources of their occurrence, but are carried out through decision-making at the regional level [3]. Modern technologies of regional government include:

1. Creation and functioning of a regional support system for small and medium-sized businesses;

2. A regional system for attracting investments based on public-private partnerships;

3. Regional support system for integration processes;

4. Development of regional innovation infrastructure;

5. Creation of a territory for innovative development, etc..

Particular attention should be paid to this type of modern management technologies as clusters and cluster policy in the region [4]. According to M. Porter, "a cluster is a group of geographically adjacent interacting companies (suppliers, manufacturers, etc.) and related organizations (educational institutions, government bodies, infrastructure companies) operating in a particular area and complementing each other" [10]. The advantages of the cluster are well enough covered in the economic literature, but from our point of view, it can also be presented as a modern technology for managing a region, which has its own characteristics and meets a number of requirements that are reflected in the "Passport" of management technology (Table 1).

Table 1. "Passport" of management technology.

\begin{tabular}{|c|c|}
\hline Management technology & Regional cluster structures \\
\hline \multicolumn{2}{|c|}{ Characteristic } \\
\hline Options & Content \\
\hline Scope of coverage & Depending on the type of cluster \\
\hline & $\begin{array}{c}\text { Determined by the scale of the participants and their } \\
\text { industry affiliation }\end{array}$ \\
\hline
\end{tabular}


Table 1. Continued

\begin{tabular}{|c|c|}
\hline Degree of influence on GRP & $\begin{array}{c}\text { Determined by the type of cluster - forestry, } \\
\text { construction, etc., as well as by scientific, financial, } \\
\text { administrative structures }\end{array}$ \\
\hline Participants & Mandatory need for coordination management \\
\hline The need for coordination management & $\begin{array}{c}\text { Depending on the existence of economic interests, } \\
\text { free entry to the cluster is possible, provided that } \\
\text { corporate interests are observed }\end{array}$ \\
\hline
\end{tabular}

The mechanisms for the effective functioning of the cluster are the conditions that facilitate the movement of information and the coordination of interests of horizontally and vertically related firms. This is due to the geographical proximity, as well as the connections that arise in scientific communities, professional associations, norms of behavior and belief in long-term and lasting relationships [13].

\section{Cluster technology}

Cluster technology provides an opportunity for constructive and effective dialogue between related organizations, their suppliers and the authorities [12]. Government investments aimed at improving the conditions for the functioning of the cluster bring benefits to many companies at once. The tasks of the authorities in this case are to identify the main clusters in which the territory is interested, through the formation of the foundations in the legislative plan, the combination of the available intellectual and scientific and educational potential, material, technical and other resources, and the determination of the strategic foundations of development [5].

One of the components of cluster technology should be a cluster initiative, which is defined as an organized attempt to increase the growth rates and competitiveness of a cluster in a particular region, involving cluster firms, the state and / or research institutes in the process [3]. A cluster initiative can come from regional authorities, from local business associations. Foreign experts identified 25 goals for supporting the development of clusters, which were grouped into six segments: regional policy; commercial cooperation; education and training; innovation and technology; cluster development; research and development of networks. At the same time, it is noted that each cluster initiative aims to improve the performance of 4-5 segments. The cluster initiative contributes to the creation of a highly developed cluster characterized by high trust between partners, rapid exchange of specific information, simultaneous rivalry and cooperation between firms, geographic proximity of cluster member enterprises, availability of public investment and a specific program for future development.

A simple transfer of certain foreign approaches and technologies in innovative management to Russian realities is often not justified [6]. The reason for this is that the models of the economic systems of the post-industrial society and Russia differ significantly in the composition of the elements, in the structure of innovation processes, as well as in the goals set. Therefore, to further assess the possibility and necessity of using innovative technologies, it is necessary to carry out their qualitative and quantitative analysis and assess the impact on the efficiency of the system of innovative management of the region. Here it is necessary to determine the feasibility of each event in accordance with the tasks set, the possibility of its implementation and the required resources. The assessment of the impact on the regional economy is carried out based on the assessment of incoming entities, enterprises of certain industries, the possibilities of influencing their economic performance, expanding the scale of activities, export potential, etc. Based on the results of the assessment, the "compatibility" of the event with other regional, and, possibly, with federal programs, the final decision is made to include the technology in the developed project of the innovative development system in the region [7]. The study of the conditions for the implementation of 
innovative technologies for managing the region is the main one. If there are no necessary conditions for implementation, then technology may be distorted or a negative result will be obtained.

When studying the conditions, it is necessary to conduct research of organizations in the region in order to identify among them innovatively active. The sample of innovatively active organizations in the region should be formed regardless of their size and types of economic activity, based on the principle that they have at least one of the following innovative processes [8]:

- Availability of proceeds from the production and sale of science-intensive products (services) or innovative products, as well as the provision of innovative services;

- Costs for the development and implementation of innovations;

- Availability of supported patents and technology licensing agreements;

- Cooperation with third-party organizations for the development and implementation of innovations

The world economy is undergoing qualitative changes associated with globalization, uneven development, aggravated competition between countries, regions, corporations. World experience shows that the progressive socio-economic development of the state and ensuring its competitiveness in the external market largely depend on the competitiveness of its constituent regions [11].

World trends are widely covered in economic literature, and the globalization of world economic processes is gaining more and more attention of political scientists, sociologists and economists. The globalization of world economic relations in the context of the growing informatization of society defines the role and functions of specific regional economies in a completely new way. The scarcity of world resources in many respects exacerbates competition for their use and expands the political influence of strong national economies, which act as integrated systems that are formed mainly at the regional level.

\section{Regional economic development paradigm}

The change in the paradigm of regional development affects almost all countries of the world - it is a global process associated with a change in the foundations of economic development [9]. The prerequisites for a paradigm change, firstly, are laid in the global economy with its new approaches to the development of countries, based on modern information technologies. The second component, reflecting a new approach to the development of regions, is the transition to a "knowledge" economy based on the priority development of innovative technologies that provide a base for the region's competitive advantages.

The development of the information and communication market makes a great contribution to the economy of "knowledge". With the transition to an information society, the proportions between routine operations and creativity, between replicating the past and innovations change [10]. Only those regions that are actively involved in this process have the opportunity to maximize the benefits of the new division of labor and participation in world economic relations. World technology leaders have learned to seize the resources of less developed countries, establishing intellectual and financial control over them. The knowledge economy is characterized by [6]:

- availability of highly professional research units with competitive advantages in certain scientific areas of modern research;

- creating conditions at the regional level for the implementation of the entire innovation cycle;

- creation of a high level of living standards, primarily for research teams (highquality education with subsequent retention of personnel; quality of life); 
- active involvement in interregional and international research teams.

The third component, reflecting the change in the regional paradigm, can be attributed to a new approach to the assessment and use of regional resources caused by changes in the structure of the world economy, with its reorientation from a raw material orientation towards the service sector and a more efficient use of natural, non-renewable resources, as well as greater importance resources such as transport, spatial, water, etc. Currently, many regions are striving to bring the use of their resources to a higher level of added value, thereby increasing their competitiveness and operational efficiency.

The fourth component of the new paradigm can be attributed to new opportunities in the integration processes and the degree of involvement of the regional economy in the world one. To implement the conceptual provisions laid down in the new paradigm, it is necessary:

1. Change of the state role in the regulation of regional development;

2. Active inclusion of the regional economy in global processes;

3. The emergence of new regions - economic leaders;

4. Transition of the regional economy to an innovative path of development with the priorities of the 5 th and 6 th technological order to v;

5. Change of management technologies;

6. Competitive ability of the regional economy;

7. Development of large-scale spatial strategies in the regions, which will attract modern large firms and their investment capital;

8. New orga nizional structures of industrial development (in par ticular and utso rsing schemes) due to the development of information technologies;

9. Changing the orthogonal logic of economic development to industrial and territorial complexes (clusters).

\section{Conclusions}

The conceptual provisions of the regional development paradigm in their implementation determine the requirements for the methods of managing the region's economy and ensure its transition to a higher stage of socio-economic development. At present, there are all the possibilities for studying the experience gained in foreign practice, which for decades has been improving the methods of regional management in a tough competitive environment. Many regions of the country have also accumulated some experience of modern methods of regional management. Sources of such technologies can be scientific units engaged in the improvement of territorial administration, regional administration units, public associations that have the opportunity to study these technologies, representatives of the legislative branch and other subjects of the regional economy. The result of such experience can be a database of management technologies for innovative development of the region.

\section{References}

1. A. Yu. Davankov, Yu. V. Markina, Bulletin of higher educational institutions, 31 (2019)

2. M. V. Egorova, Innovation system of the region: basic models of analysis and directions of development, 233 (2020)

3. V. M. Kolomytsev, Formation of a long-term innovative strategy for the development of the Russian economy and mechanisms of its implementation, 377 (2019)

4. L. V. Kurakova, Formation of the innovation system as a strategic direction of the region's development, 201 (2018) 
5. I. A. Kuteev, The innovative component of the strategy for the development of a selfsufficient, stably dynamic region, 473 (2017)

6. E. S. Nikishina, N. M. Filimonova, Problems of modern economy, 295-298 (2018)

7. On special economic zones in the Russian Federation: Federal Law of the Russian Federation of July 22, 116-FZ (2005)

8. On the approval of the Strategy of the innovation development of the Russian Federation for the period up to 2020: the order of the Government of the Russian Federation from December 8, 2227-r (2011)

9. S.V. Popov, D.A. Kolesnichenko, Innovative Development of Russia: Regional Aspect, 36 (2020)

10. K. Yu. Prokofiev, Regional economy: theory and practice, 22 (2017)

11. K. Yu. Prokofiev, Scientific and technical bulletin of SPbSPU, Economic Sciences, 94 (2020)

12. E. V. Sumina, Actual problems of the humanities and natural sciences, 83 (2019)

13. E.V. Sumina, V.A. Chalkin, Scientific and technological development of territories as the basis of the innovative strategy of the Russian economy, 210 (2018) 